\title{
Effects of Neonatal Treatment with 6-Hydroxydopamine and Endocrine Disruptors on Motor Activity and Gene Expression in Rats
}

\author{
Yoshinori Masuo, ${ }^{\$ 1}$ Masami Ishido $^{2}$, Masatoshi Morita ${ }^{2}$, Syuichi Oka ${ }^{1}$ \\ ${ }^{1}$ National Institute of Advanced Industrial Science and Technology (AIST), Tsukuba Central 6, 1-1-1 \\ Higashi, Tsukuba 305-8566, Japan; ${ }^{2}$ Endocrine Disruptors and Dioxin Research Projects, National Institute \\ for Environmental Studies, 16-2 Onogawa, Tsukuba 305-8506, Japan
}

\begin{abstract}
SUMMARY
To investigate the mechanisms underlying motor hyperactivity, we performed intracisternal injection of 6-hydroxydopamine or endocrine disruptors in rats on postnatal day 5. 6-Hydroxydopamine $(100 \mu \mathrm{g}, 488 \mathrm{nmol})$ caused a significant increase in spontaneous motor activities at 4 weeks of age. Gene-expression profiling using a cDNA membrane array revealed alterations in several classes of gene at 8 weeks of age. In the midbrain, gene expression was enhanced in dopamine transporter 1; a platelet-derived growth factor receptor; dopamine receptor D4; galanin receptor 2; arginine vasopressin receptor 2 ; neuropeptide $Y$; tachykinin 2; and fibroblast growth factor 10 . Expression was also enhanced in the glutamate/aspartate transporter gene in the striatum. Rats received an endocrine disruptor (87 nmol), such as bisphenol $A$, nonylphenol, $p$ octylphenol, or diethylhexylphthalate, which also caused motor hyperactivity at 4 weeks.
\end{abstract}

Reprint requests to: Y. Masuo, Ph.D., Human Stress Signal Research Center, National Institute of Advanced Industrial Science and Technology (AIST), Tsukuba Central 6, 1-1-1 Higashi, Tsukuba, 305-8566 Japan; e-mail: y-masuo@aist.go.jp

${ }^{8} \mathrm{Y}$. Masuo and M. Ishido contributed equally to this study. This work is dedicated to the late Dr. Shuzo Watanabe for his guidance and encouragement to Y.M. in the study of hyperkinetic disorder model rats at the National Center of Neurology and Psychiatry, National Institute of Neuroscience.
The effects of bisphenol $A$ on motor activity were dose-dependent from 0.87 to $87 \mathrm{nmol}$. The phenols caused a deficit in dopamine neurons, similarly to the deficit caused by 6-hydroxydopamine. Gene-expression profiles after treatment with endocrine disruptors showed variation and differed from those of 6hydroxydopamine. The results suggest that neonatal treatment with environmental chemicals can generate an animal model of attention-deficit hyperactivity disorder, in which clinical symptoms are pervasive.

\section{KEYWORDS}

motor hyperactivity; bisphenol A; nonylphenol; octylphenol; diethylhexylphthalate; DNA array

\section{INTRODUCTION}

Patients with attention-deficit hyperactivity disorder (ADHD) show inattention, motor hyperactivity, and impulsivity. Although ADHD is known as a developmental disorder, the etiology is not yet clear. To understand the mechanisms of ADHD, a number of studies have been performed in several kinds of animal models showing genetically derived hyperactivity or naturally occurring behavioral variability. Lesion studies and pharmacological treatment were also reported 
(Viggiano, 2003). Although the mesocorticolimbic dopamine (DA) system has been suggested to be involved in ADHD, whether the DA system is hypo- or hyper-functioning remains to be elucidated. Because treatment with methylphenidate often attenuates hyperactivity (Swanson, 2003), a hyperkinetic child with neonatal 6-hydroxydopamine (6-OHDA) lesions (Shaywitz, 1976a, b) is a valuable model of ADHD in view of motor activity. Rats with a deficit in the development of DA neurons show motor hyperactivity during the juvenile period (Davids, 2002a; Heffner, 1982; Shaywitz, 1976a, b; Zhang, 2001), which can be attenuated by psychostimulants like those used to treat clinical ADHD (Swanson, 1998; Volkow, 2002).

It has been demonstrated that exposure to environmental chemicals that mimic the action of estrogen disrupts endocrine function (Markey, 2002). Most of these compounds, the so-called endocrine disruptors (EDs), are derived from industrial products and have been detected in the human umbilical cord and cord serum (Mori, 2001). Several lines of evidence suggest that estrogen affects the central DA system (Kuppers, 2001). However, the effects of EDs on the central nervous system have not been well documented. Therefore, it would be of interest to study the effects of neonatal treatment with EDs on the DA system and on spontaneous motor activity (SMA) in the rat.

To understand the mechanisms underlying motor hyperactivity caused by the lack of a mesocorticolimbic DA system, we generated neonatal 6-OHDA lesions in the rat. The effects of neonatal treatment with EDs, such as bisphenol A, nonylphenol, $p$-octylphenol and diethylhexylphthalate (DEHP), were also studied to examine whether these chemicals can exert effects on brain function, as shown for other environmental chemicals (Palanza, 1999). Spontaneous motor activity was measured at 4 weeks of age, a juvenile period. The expression of multiple genes was analyzed by the cDNA macroarray method using a nylon membrane array in the striatum and midbrain. This method provides results that are more reproducible than the microarray, and several groups have applied this method to their studies on the central nervous system (Cho, 2002; Hida, 2003; Napolitano, 2002) and PC12 cells (Foehr, 2000). Immunohistochemical studies were also performed for the detection of tyrosine hydroxylase (TH) to examine the integrity of DA neurons in the midbrain.

\section{EXPERIMENTAL}

\section{Treatment of animals}

The present study was conducted in accordance with the Guidelines for the Care and Use of Laboratory Animals in the National Institute of Advanced Industrial Science and Technology, Japan, and in the National Institute for Environmental Studies, Japan. Female Wistar rats were purchased from Clea Japan (Tokyo, Japan) 2 weeks after becoming pregnant. The rats were individually housed in an acrylic cage at $22^{\circ} \mathrm{C}$ with tap water and laboratory chow (Oriental Yeast Corp., Tokyo, Japan) ad libitum. The breeding room was illuminated from 07:00 to 19:00 $\mathrm{h}$ in 12-h cycles.

Male pups were selected at 5 days after birth. The body weight of the animals was $\sim 10 \mathrm{~g}$. Desipramine (Sigma-Aldrich, St. Louis, Missouri, USA), a blocker of noradrenaline (NA) uptake, was administered intraperitoneally at $25 \mathrm{mg} / \mathrm{kg}$ body wt to protect adrenergic neurons from the effects of 6-OHDA. Thirty minutes later, the rats received 100 micrograms $(488 \mathrm{nmol})$ of 6-OHDA hydrobromide (Sigma-Aldrich) in $0.9 \% \mathrm{NaCl}$ containing $0.04 \%$ ascorbic acid (10 microliters) intracisternally. For controls, the vehicle was injected under similar conditions. We also performed an intracisternal administration of EDs, purchased from Wako Pure Chemical Ind. (Tokyo, Japan), without desipramine pretreatment. An ED, 
such as bisphenol A, nonylphenol, $p$-octylphenol, or DEHP, was dissolved in olive oil (Nacalai Tesque, Kyoto, Japan) to $8.7 \mathrm{mM}$. The pups received an intracisternal injection of $87 \mathrm{nmol}$ in a volume of 10 microliters. In some experiments, bisphenol A was dissolved from 0.087 to $87 \mathrm{nmol}$ in 10 microliters. For the control, the same volume of olive oil was injected intracisternally under similar conditions. Next, the pups were randomly assigned to lactating dams, 5-7/dams and weaned at 3 weeks of age.

\section{Measurement of spontaneous motor activity}

We measured the SMA of 4-5 week-old rats using the Supermex activity-monitoring system (Muromachi Kikai, Tokyo, Japan), as described previously (Ishido, 2002; Masuo, 1995). Briefly, each rat was placed in a transparent plastic home cage $(24 \times 30 \times 18 \mathrm{~cm}$, width $\times$ depth $\times$ height $)$, located in a sound-attenuating chamber $(45 \times 50 \times 45$, internal width $\times$ depth $\times$ height) illuminated in a 12 $\mathrm{h} / 12 \mathrm{~h}$ light/dark cycle (light: 7:00-19:00). A Supermex sensor box $(83 \times 53 \times 35 \mathrm{~mm}$, width $\times$ depth $\times$ height) mounted in the center of the ceiling of a sound-attenuating chamber detected motor activity, and sensor signals were transmitted by an interface device (DI-032), to a personal computer. The signals were converted to the number of movements with CompACT AMS software.

\section{Brain dissection}

The rats were decapitated at 8 or 10 weeks of age, and whole brains were rapidly removed and put on an ice-cold glass plate with the ventral surface upward. The olfactory tubercles were first dissected from both hemispheres. Next, the frontal cortex was separated from the olfactory bulb with a transverse section at the level of the posterior limb of the frontal cortex. After the olfactory bundle and hypothalamus were removed, the rest of the brain was placed with the dorsal surface upward. Both hemispheres were separated to the depth of the corpus callosum and the lateral ventricle was exposed. The cerebral cortex and striatum in each hemisphere were removed and the striatum was gently separated from the cortex. Other limbic areas containing the nucleus accumbens and septum were separated by the following sections from the rest of the brain: a section at the plane between the ventral edge of the lateral ventricle and the anterior commissure, a transverse section at the posterior limb of the septum, and a transverse section at the level of the posterior limb of the frontal cortex as described above. The region removed was combined with the olfactory tubercles previously dissected. The midbrain was dissected using transverse sections from the rest of the brain at the anterior and posterior limbs of the substantia nigra. All tissue samples were frozen in liquid nitrogen and stored at $-80^{\circ} \mathrm{C}$.

\section{Catecholamine contents}

Catecholamine levels were measured in the frontal cortex, the striatum, and in other limbic areas containing the nucleus accumbens and the septum and olfactory tubercles in rats at 10 weeks of age. Each tissue sample was homogenized in 0.5 $\mathrm{mL}$ of $0.2 \mathrm{M}$ perchloric acid containing $100 \mu \mathrm{M}$ EDTA-2Na and $100 \mathrm{ng}$ of isoproterenol (internal standard). After centrifugation at $20,000 \times \mathrm{g}$ for 15 min, the supernatant was transferred to another tube and the $\mathrm{pH}$ was adjusted to 3 by adding $1 \mathrm{M}$ sodium acetate. After filtration through a filter having an average pore diameter of $0.45 \mu \mathrm{m}$, the samples were subjected to high-performance liquid chromatography (HPLC). The catecholamines were separated using a reverse-phase column, 4.6 $\times 150 \mathrm{~mm}$, Eicompak MA-5ODS (Eicom, Kyoto, Japan) maintained at $25^{\circ} \mathrm{C}$. The mobile phase was a $0.83 \mathrm{M}$ citrate-sodium acetic acid buffer, $\mathrm{pH} 3.5$, containing $230 \mathrm{mg} / \mathrm{L}$ of octane-sulfonic acid, $5 \mathrm{mg} / \mathrm{L}$ of EDTA-2Na, and $17 \%$ methanol at a 
flow rate of $1.0 \mathrm{~mL} / \mathrm{min}$. Dopamine and NA were detected by an electrochemical detector (ECD-100, Eicom) at $+750 \mathrm{mV}$ vs. $\mathrm{Ag} / \mathrm{AgCl}$. The respective retention times for NA, DA, and isoproterenol were 5.2, 11.0, and 14.5 minutes. The results were calculated as nanograms per milligram of protein.

\section{Immunohistochemistry}

In some experiments, the whole brain was immediately removed after the decapitation of 8 -week-old rats. Each brain was fixed with $10 \%$

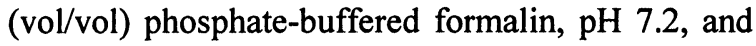
embedded in paraffin. The tissue was cut into 5micrometer-thick serial sections using a microtome and processed for immunohistochemical staining using avidin-biotin alkaline phosphatase. Briefly, sections were permeabilized with $5 \mathrm{~mL} / \mathrm{L}$ Triton $\mathrm{X}-100$ in phosphate-buffered saline (PBS) and blocked for $30 \mathrm{~min}$ with $100 \mathrm{~g} / \mathrm{L}$ normal horse serum and $40 \mathrm{~g} / \mathrm{L}$ bovine serum albumin at $4{ }^{\circ} \mathrm{C}$. Next, the sections were incubated with the primary monoclonal antibody anti-tyrosine hydroxylase $(\mathrm{TH})$ (1:100; Sigma-Aldrich) in the presence of $40 \mathrm{~g} / \mathrm{L}$ bovine serum albumin and $0.5 \mathrm{~mL} / \mathrm{L}$ Triton X-100. After washing with PBS containing $1 \mathrm{~mL} / \mathrm{L}$ Tween 20 , the sections were incubated with a biotinylated secondary antibody, goat anti-mouse IgG (Lab Vision Corp., Fremont, California, USA). The biotinylated molecules were further incubated for 10 min with streptavidin-conjugated alkaline phosphatase at room temperature. Tyrosine hydoxylase immunoreactivity was visualized with 5-bromo-4-chloro-3indolyl phosphate/nitroblue tetrazolium (Lab Vision Corp.) and counterstained with $1 \%$ methyl green.

\section{DNA array analysis}

For the investigation of muitiple-gene expression, the striatum and midbrain from 8-week-old rats were processed to the cDNA macroarray according to the manufacturer's protocol (BD Biosciences Clontech, Palo Alto, California, USA). Two striata taken from both hemispheres in one rat were pooled as one sample ( $\sim 60 \mathrm{mg}$ ) and the midbrain obtained from one rat $(\sim 80 \mathrm{mg})$ was used as one sample. We dissected the whole midbrain rather than the ventral mesencephalon containing the substantia nigra and ventral tegmental area (VTA) as more than $50 \mathrm{mg}$ of tissue was required to perform the cDNA macroarray. Total RNA was extracted from the tissue sample and quantified by UV spectroscopy; the quality was estimated by capillary electrophoresis. After reverse transcription, the cDNA probe was labeled with $\left[\alpha{ }^{32} \mathrm{P}\right] \mathrm{dATP}$, PB 10204 (110 TBq/mmol, Amersham Bioscience, Piscataway, New Jersey, USA) and hybridized with an Atlas Rat 1.2 Array (BD Biosciences Clontech). The array consisted of a nylon membrane on which 1,176 kinds of cDNA were spotted. In each experiment, one array membrane was used for one sample. Radiolabeled membranes were exposed to imaging plates (Fujifilm, Tokyo, Japan) and gene expression intensities were analyzed using the Fluorescent Image Analyzer FLA-3000G (Fujifilm) and the AtlasImage software (BS Biosciences Clontech). We performed 3 experiments with 3 rats independently and calculated the mean value of the gene-expression ratio of the sham-operated controls. The differences in gene expression were considered above the threshold when the signal intensities differed by more than 3 and the expression ratios differed by more than 1.69.

\section{Statistical analysis}

The effects of treatment with 6-OHDA or EDs on SMA were examined by analysis of variance (ANOVA) of repeated measure. Among four kinds of ED, the effects were compared by two-way ANOVA, followed by post-hoc Scheffé test for planned comparisons. For catecholamine levels, Student's $t$-test was applied to determine the 
TABLE 1

Effects of neonatal treatment with 6-OHDA on endogenous catecholamine levels in the rat brain

\begin{tabular}{lccc}
\hline Catecholamine & Frontal cortex & Striatum & $\begin{array}{c}\text { Limbic area without } \\
\text { striatum }\end{array}$ \\
\hline Dopamine & & & \\
Control & $1.41 \pm 0.29(6)$ & $126.04 \pm 10.97(6)$ & $50.53 \pm 5.79(6)$ \\
Treated & $0.80 \pm 0.11(16)^{*}$ & $3.67 \pm 0.63(16)^{* *}$ & $11.50 \pm 1.35(16)^{* *}$ \\
& $-43.3 \%$ & $-97.1 \%$ & $-77.2 \%$ \\
Noradrenaline & & & $23.71 \pm 1.16(6)$ \\
Control & $6.27 \pm 0.56(6)$ & $-1.90 \pm 0.17(6)$ & $27.51 \pm 2.44(16)$ \\
Treated & $6.42 \pm 0.52(16)$ & $1.76 \pm 0.17(16)$ & \\
\hline
\end{tabular}

Rats received intracisternal administration of 6-OHDA after intraperitoneal injection of desipramine at 5 days of age. At 10 weeks of age, rats were sacrificed and catecholamine levels were measured by HPLC-ECD in the frontal cortex, striatum, and other limbic area (septum, nucleus accumbens, and olfactory tubercles). Results are expressed as $\mathrm{ng} / \mathrm{mg}$ protein, and mean \pm S.E.M. (number of rats).

${ }^{*} P<0.05,{ }^{* *} P<0.01$ vs. respective control value (Student's $t$-test).

significance of the differences between values obtained in rats with neonatal treatment and the respective sham-operated controls. According to the two-tailed probability, $\mathrm{p}<0.05$ was considered statistically significant.

\section{RESULTS}

\section{Endogenous catecholamine levels after neonatal treatment with 6-OHDA}

We injected 6-OHDA intracisternally into the rat at 5 days of age and the catecholamine contents were measured by HPLC-ECD. As shown in Table 1, neonatal treatment with 6-OHDA significantly decreased the endogenous levels of DA in the frontal cortex, striatum, and other limbic areas containing the nucleus accumbens, septum, and olfactory tubercles in rats at 10 weeks of age. Among these regions, decreases of DA levels were most significant in the striatum. The levels were diminished by $97 \%$ in this region. DA contents in the lesioned rats were significantly lower than in the controls by $43 \%$ and by $77 \%$ in other limbic areas and in the frontal cortex, respectively. The endogenous levels of NA did not show any significant changes in either region.

\section{Effects of neonatal 6-OHDA lesions on SMA in juvenile rats}

As shown in Fig. 1, SMA showed high levels during the dark phase and low counts during the light phase. In the sham-operated control rats $(n=14)$, SMA was $5020 \pm 465$ counts (mean \pm SEM) in the first $2 \mathrm{~h}$ of the dark phase, but these levels had recovered by $8 \mathrm{~h}$ to $2624 \pm 297$. The activity levels were then enhanced again, peaking at $12 \mathrm{~h}(3503 \pm 276)$. By contrast, the rats showed low levels of SMA during the light phase from $473 \pm 84$ to $1480 \pm 198$. The SMA in $6-$ OHDAtreated rats $(n=14)$ was significantly higher than 


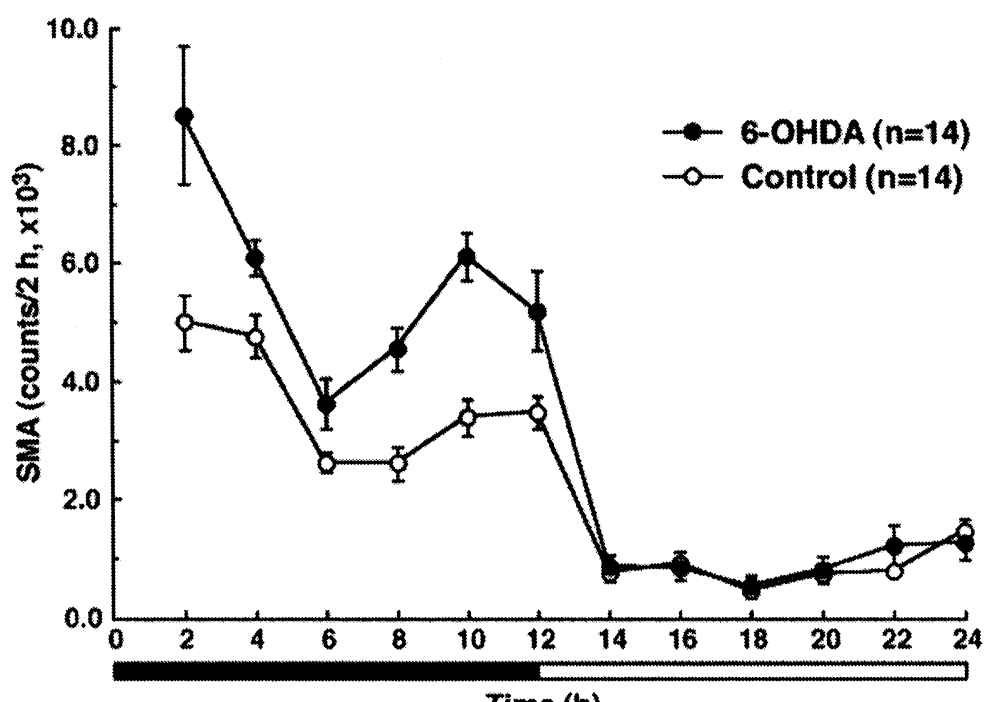

Time (h)

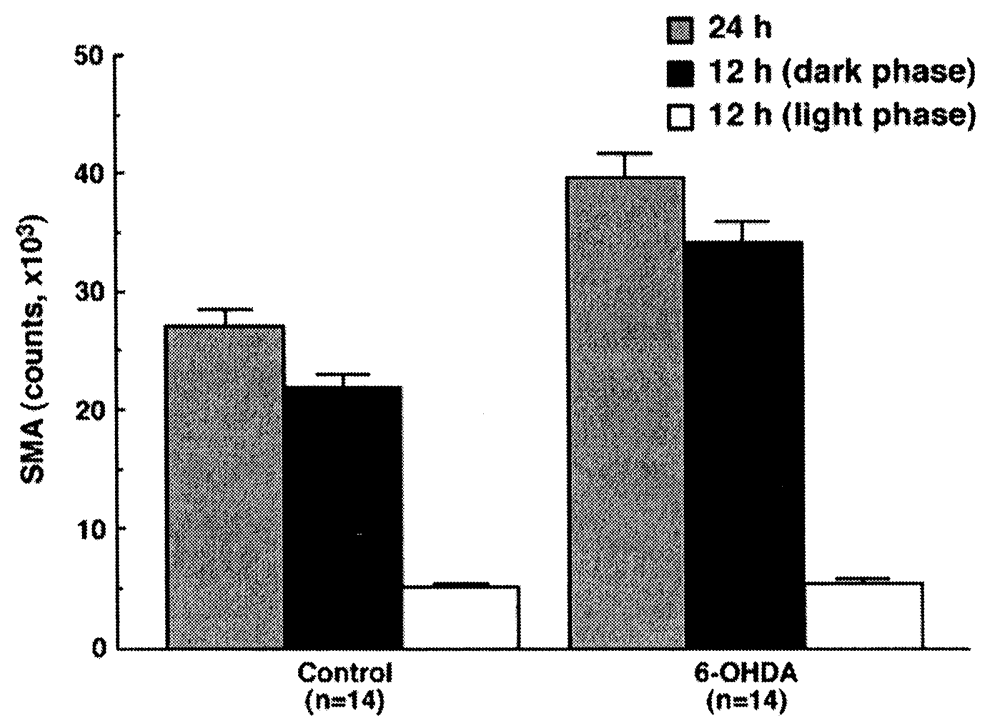

Fig. 1: Effects of neonatal treatment with 6-OHDA on spontaneous motor activity (SMA) at 4 weeks of age. Male Wistar rats received intraperitoneal injections of desipramine $(25 \mathrm{mg} / \mathrm{kg})$ followed by intracisternal administration of 6-OHDA ( $100 \mu \mathrm{g}$ in $10 \mu \mathrm{L})$. Controls received $10 \mu \mathrm{L}$ of the vehicle used for 6-OHDA $(0.04 \%$ ascorbic acid in saline). SMA was measured using a Supermex system (Muromachi Kikai, Tokyo, Japan) at 4-5 weeks of age in a $12 \mathrm{~h} / 12 \mathrm{~h}$ light/dark cycle. Upper: results represented as mean $\pm \mathrm{SEM}(\mathrm{n}=$ number of animals) of counts per $2 \mathrm{~h}$. The period of time 0-12 was the dark phase. Lower: the counts of SMA accumulated during $24 \mathrm{~h}$ or $12 \mathrm{~h}$ periods in rats (number of animals). SMA in 6-OHDA-treated rats was significantly higher than that in controls during a $24 \mathrm{~h}$ period and in the dark phase; $P=0.0004$ and $P<0.0001$, respectively, by ANOVA of repeated measure. 
in controls during a $24 \mathrm{~h}$ period $[F(1,286)=16.622$, $P=0.0004$ by ANOVA of repeated measure] and in the dark phase $[F(1,130)=20.741, P=0.0001]$. The differences between the 6-OHDA-treated and the ontrol rats were not statistically significant during the light phase $[F(1,130)=0.129, P=0.7223]$. Thus, neonatal treatment with 6-OHDA did not cause a modification in motor activity with the day-night cycle. The general behavior in rats with 6-OHDA lesions did not differ from that of controls. Indeed, an increase in rearing behavior was not evident, although we did not quantify the rearing. Moreover, stereotyped behavior was not observed after treatment with 6-OHDA.
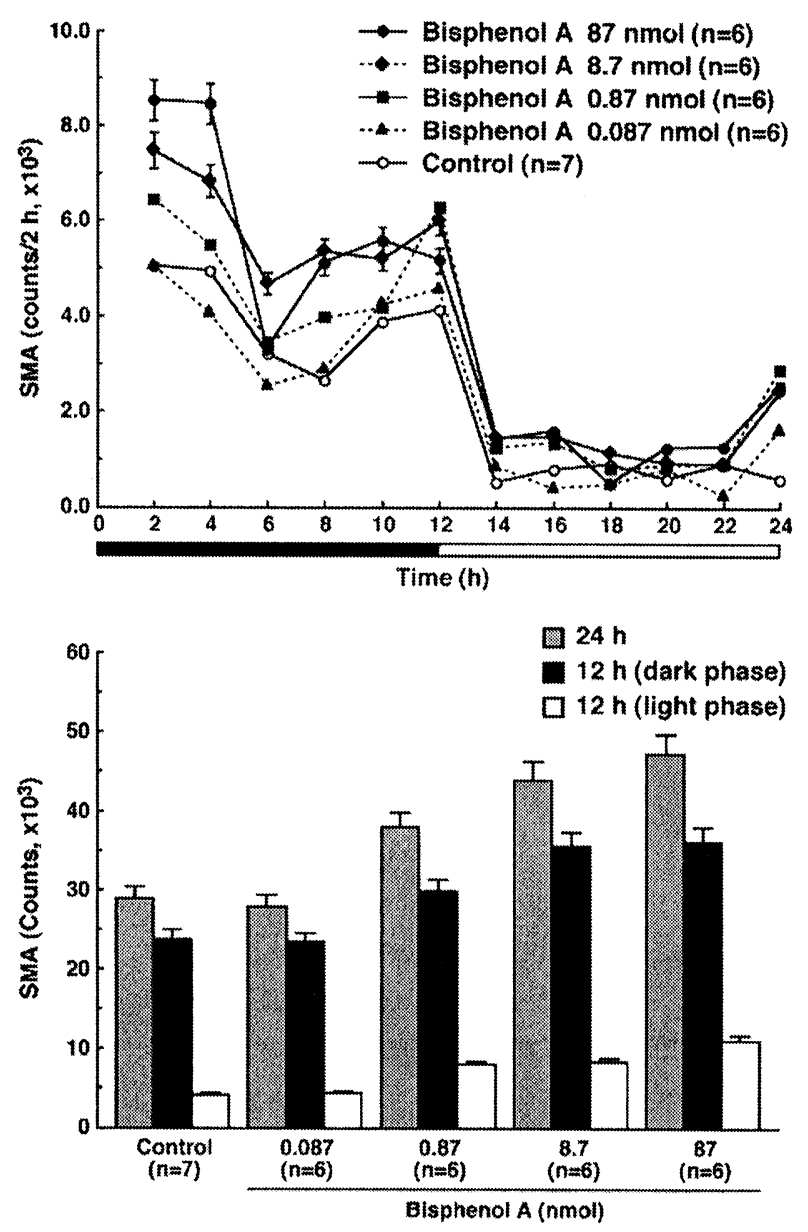

\section{Effects of neonatal treatment with EDs on SMA in juvenile rats}

We also measured SMA after neonatal treatment with EDs. Figure 2 shows SMA in rats at 4 weeks of age after treatment with bisphenol A. The pattern of SMA in sham-operated control rats $(n=7)$ was similar to that of the controls for 6OHDA-lesioned animals. Bisphenol A caused a dose-dependent increase in SMA. With $87 \mathrm{nmol}$ of bisphenol A $(n=6)$, the differences between the treated and control animals were statistically significant during $24 \mathrm{~h}[F(1,121)=47.692, P<0.0001]$, in the dark phase $[F(1,55)=44.375, P<0.0001]$ and
Fig. 2: Effects of neonatal treatment with bisphenol A on SMA at 4 weeks of age. Bisphenol $\mathrm{A}$ dissolved in 10 $\mu \mathrm{L}$ of olive oil was injected into male rats intracisternally at 5 days of age. Controls received the vehicle. SMA was measured as described in Fig. 1. Upper: results expressed as mean \pm SEM $(n=$ number of rats) of counts per $2 \mathrm{~h}$. Lower: the counts of SMA during $24 \mathrm{~h}$ or $12 \mathrm{~h}$ periods in rats (number of animals). SMA in bisphenol Atreated rats was significantly higher than that in controls at doses from 0.87 to $87 \mathrm{nmol}$ during either period ( $p<0.05$ by ANOVA of repeated measure). $0.087 \mathrm{nmol}$ of bisphenol A did not cause significant changes in SMA. 
light phase $[F(1,55)=24.746, P=0.0004]$. SMA was also enhanced after treatment with $8.7 \mathrm{nmol}$ of bisphenol A $(n=6)$.

Significant differences were found between the two groups during $24 \mathrm{~h}[F(1,121)=19.318$, $P=0.0011]$, in the dark phase $[F(1,55)=20.589$, $P=0.0008]$ and light phase $[F(1,55)=12.319$, $P=0.0049]$. The lower dose, $0.87 \mathrm{nmol}(\mathrm{n}=6)$, also caused significant increases during $24 \mathrm{~h}$ $[F(1,121)=10.818, P=0.0072]$, in the dark phase $[F(1,55)=4.890, P=0.0491]$ and light phase $[F(1,55)=6.325, P=0.0287]$. SMA levels were not significantly increased in rats treated with $0.087 \mathrm{nmol}$ of bisphenol A $(\mathrm{n}=6)$ during $24 \mathrm{~h}$ $[F(1,121)=0.005, P=0.9454]$, in the dark phase $[F(1,55)=0.017, P=0.8990]$ and light phase $[F(1,55)=0.014, P=0.9085]$.

Fig.3 shows SMA in 4-week-old rats after neonatal treatment with $87 \mathrm{nmol}$ of nonylphenol, p-octylphenol, or DEHP. All chemicals caused motor hyperactivity, not only during the dark phase but also during the light phase. A significant difference was not found among these three chemicals and bisphenol $\mathrm{A}$ at $87 \mathrm{nmol}$ during $24 \mathrm{~h}$ $[F(3,209)=1.356, P=0.2863]$, in the dark phase $[F(3,95)=1.952, P=0.1555]$ and in the light phase $[F(3,95)=0.860, P=0.4786]$. As shown in Fig. 4, treatment with bisphenol $\mathrm{A}$, nonylphenol, $p$-octylphenol, or DEHP significantly enhanced SMA. The differences between bisphenol A-treated and control animals were statistically significant during $24 \mathrm{~h}[F(1,121)=66.733, P<0.0001]$, in the dark phase $[F(1,55)=50.343, P<0.0001]$ and in the light phase $[F(1,55)=15.858, P=0.0022]$, although the control rats were not the same as those in Fig. 2. With nonylphenol, hyperactivity was significant during $24 \mathrm{~h}[F(1,132)=26.467, P=0.0002]$, in the dark phase $[F(1,60)=17.399, P=0.0013]$ and light phase $[F(1,60)=9.700, P=0.0089]$.

The effects of $p$-octylphenol were evident during $24 \mathrm{~h}[F(1,110)=44.111, P<0.0001]$, in the dark phase $[F(1,50)=28.024, P=0.0004]$ and light phase $[F(1,50)=14.060, P=0.0038]$. SMA in rats treated with DEHP significantly differed from controls during $24 \mathrm{~h}[F(1,110)=250.751, P<0.0001]$, in the dark phase $[F(1,50)=107.430, P<0.0001]$ and light phase $[F(1,50)=27.246, P=0.0004]$. Nonylphenol in particular however, caused hyperactivity at the first $2 \mathrm{~h}$ of the dark phase (Fig. 3, $P<0.0001$, Student's $t$-test). Among the other EDs, bisphenol A induced a slight but significant increase $(P=0.0319)$ with no statistical alterations with $p$-octylphenol and DEHP. Similar to the effects of the 6-OHDA lesions, the general behavior in rats with neonatal ED treatment was normal. For example, rearing behavior and stereotyped behavior were not evident.

\section{Tyrosine hydroxylase immunoreactivity}

We performed immunohistochemistry for $\mathrm{TH}$. As shown in Fig. 5, in control rats, strong $\mathrm{TH}$ immunoreactivity was observed in the VTA and the SNC. Neonatal treatment with nonylphenol and $p$-octylphenol clearly attenuated the immunoreactivity in these regions. Treatment with 6-OHDA and bisphenol $\mathrm{A}$ also diminished $\mathrm{TH}$ immunoreactivity (Ishido, 2004). On the other hand, DEHP did not alter the immunoreactivity in either region (data not shown).

\section{Multiple gene expression}

The integrity of total RNA extracted from the brain was examined in all samples. A ratio of the yield of RNA/tissue weight was at least $1.00 \times 10^{-3}$ and OD $260 \mathrm{~nm} / 280 \mathrm{~nm}$ of the RNA was not less than 2.0. After electrophoresis of RNA, rRNA subunit bands at $18 \mathrm{~S}$ and $28 \mathrm{~S}$ indicated the presence of intact RNA. Indeed, the $28 \mathrm{~S} / 18 \mathrm{~S}$ ratio of rRNA was around 1.5. The hybridization intensities were calculated for every gene on the array for control and treated animals, and a ratio of the summed intensities was made.

Tables 2 and 3 show altered gene expression in the midbrain and striatum in rats exposed to neonatal treatment with 6-OHDA, bisphenol A, 

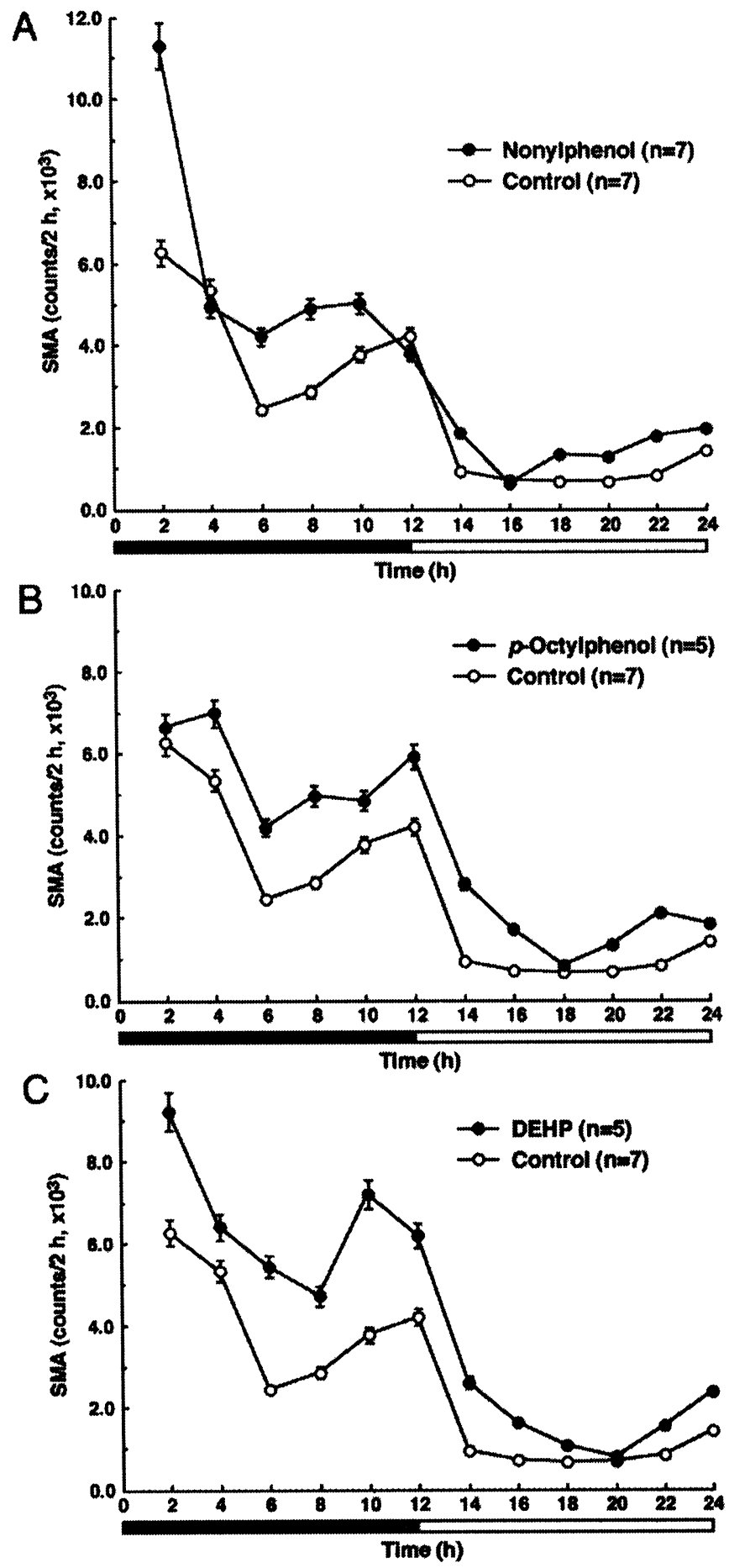

Fig. 3: Effects of neonatal treatment with nonylphenol, $p$-octylphenol, or DEHP on rat SMA. Each chemical compound $(87 \mathrm{nmol})$ dissolved in $10 \mu \mathrm{L}$ of olive oil was injected intracisternally at 5 days of age. The vehicle was similarly injected for controls. SMA was measured at 4 weeks of age as described in Fig. 1. Results are represented as counts per $2 \mathrm{~h}$ and are means \pm SEM ( $n=$ number of animals). All of these chemicals caused significant motor hyperactivities during a $24 \mathrm{~h}$ period $(p<0.001$ by ANOVA of repeated measure). 


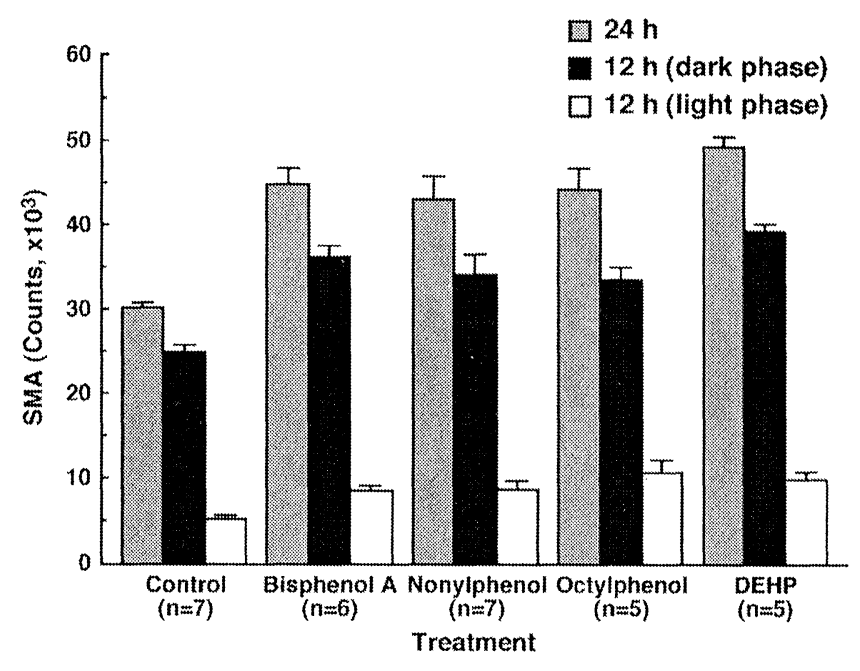

Fig. 4: SMA in rats with neonatal treatment with EDs. Bisphenol A, nonylphenol, $p$ octylphenol, or DEHP at the dose of 87 $\mathrm{nmol} / 10 \mu \mathrm{L}$ was injected into the rat intracisternally at 5 days of age. SMA was measured at 4 weeks of age as described in Fig. 1. Results are expressed as counts of SMA during $24 \mathrm{~h}$ or $12 \mathrm{~h}$ periods and are means \pm SEM (number of animals). The effects of bisphenol $A$ presented in this figure were examined independently of Fig. 2. All of these chemicals caused significant motor hyperactivities during the dark and light phases $(p<0.01$ by ANOVA of repeated measure).
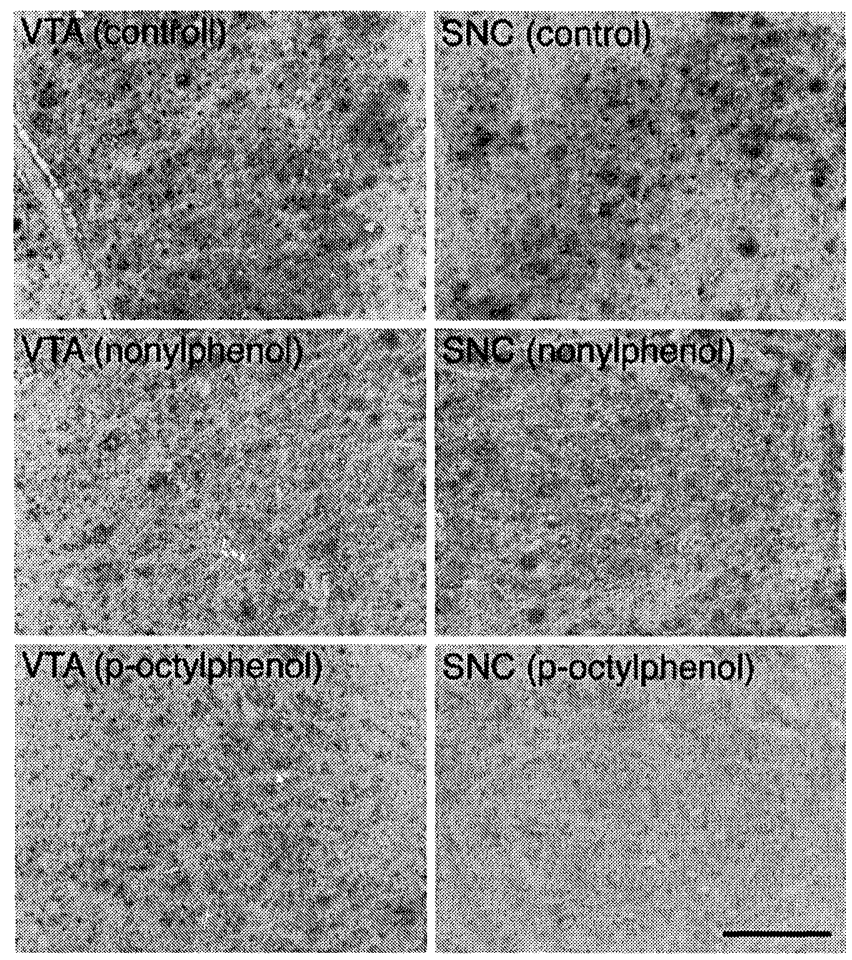

Fig. 5: TH immunoreactivity in the VTA and substantia nigra pars compacta (SNC) in rats treated with nonylphenol or p-octylphenol. Sagittal sections were made from the brain of rats at 8 weeks of age and processed to immunohistochemistry for $\mathrm{TH}$ using avidin-biotin alkaline phosphatase. TH immunoreactivities were visualized with 5-bromo-4chloro-3-indolyl phosphate/nitroblue tetrazolium and counterstained with methyl green. TH immunoreactivites were highly observed in the SNC and VTA in control animals. Neonatal treatment with nonylphenol and $p$ octylphenol attenuated the immunoreactivities in these regions. Bar: $100 \mu \mathrm{m}$. 
nonylphenol, $p$-octylphenol, and DEHP. The results are expressed as an expression ratio, with gene expression in treated rats per sham-operated controls. Each value is the mean of results from three sets of experiments ( $n=3$ animals). The tables list the genes in which the expression was above the threshold (signal intensities differed by more than 3 and expression ratios differed by more than 1.69) in rats treated with 6-OHDA. Therefore, no change (-) and not determined because of low intensities of gene expression (ND) are contained in EDs-treated animals. All the DA-related genes contained in the Atlas Rat 1.2 are represented, even if the expression was not altered by either chemical compound.

As shown in Table 2, increased expression was observed in the midbrain after neonatal 6-OHDA lesions in the c-fos proto-oncogene, Cyp4f6, Dat1, Nhe1, Atp12a, Scp2, Hsd3b, Cyp17, Tk1, Hspala, Pdgfrb, Insr, Drd4, Galr2, Avpr2, Npy, Tac2, Grp, Fgf10, Nppc, and in Igfbp6. Among the EDs, bisphenol A did not change the expression of genes for which 6-OHDA lesions caused alterations. Nonylphenol and $p$-octylphenol increased only Nppc expression. On the other hand, treatment with DEHP enhanced the expression of Glast, Sod1, HSP90-beta, Npy, Fgf10, and Nppc. Table 3 shows altered gene expression in the striatum. 6-OHDA lesions increased the expression of Scn $1 b$, Glast, Atp6l, Sod1, and HSP90-beta. No change was observed after treatment with nonylphenol and DEHP. $p$-Octylphenol induced Cyp4f6 and Galr2.

\section{DISCUSSION}

After treatment with 6-OHDA, the endogenous contents of DA were significantly lower than those in the controls in the frontal cortex, striatum, and in other limbic areas, such as the nucleus accumbens, septum, and olfactory tubercles. Dopamine levels were almost completely abolished in the striatum. Nevertheless, NA levels did not show significant changes in either region, indicating that the adrenergic neurons might be intact because of desipramine pretreatment. The DA-specific lesions caused significant increases in SMA at 4-5 weeks of age, similarly to the results of our previous studies (Masuo, 2002). Yet, the degree of increment of SMA is lower than that in previous studies (Davids, 2002b; Zhang, 2001, 2002), and significant changes were not observed during the light phase. This variation might be due to different methods used for measuring motor activity. We detected all kinds of motor behavior during $24 \mathrm{~h}$ under the 12-h dark and $12 \mathrm{~h}$-light conditions, which can result in adaptation to the environment. In previous studies by other groups, the locomotor activity was detected for 90 min during the light phase in a novel environment to investigate reactivity to the novelty of the situation.

Similarly, SMA was increased by neonatal treatment with bisphenol A, nonylphenol, p-octylphenol, and DBP. Hyperactivity was significant not only during the dark phase but also during the light phase. The results of this experiment suggest that EDs can cause a deficit in sleep. The day/night cycle was maintained, however, because a rhythm shift was not observed. Nonylphenolinduced hyperactivity was extremely high at the first $2 \mathrm{~h}$, suggesting that these rats might have difficulty in adapting to a novel environment. Indeed, rats passed the dark phase in a soundattenuating chamber for the first time. The hyperactivity during the $24 \mathrm{~h}$ period after EDs treatment raises the question of whether EDs are more potent than 6-OHDA in inhibiting the development of DA neurons or whether the mechanisms of EDs-induced motor hyperactivity differ from those of 6-OHDA lesions. The former may be not the case, however, because rats with 6-OHDA lesions in which the endogenous DA contents were almost completely abolished did not show hyperactivity in the light phase.

The results of the behavioral studies prompted us to perform immunohistochemistry for $\mathrm{TH}$. We found an attenuation in immunoreactivity in the VTA and 


\section{TABLE 2}

Gene expression in the midbrain altered by 6-OHDA or EDs

\begin{tabular}{|c|c|c|c|c|c|}
\hline \multirow{2}{*}{ Classification, Gene name } & \multicolumn{5}{|c|}{ Expression ratio } \\
\hline & \multicolumn{4}{|c|}{ 6-OHDA Bisphenol A Nonylphenol $p$-Octylphenol } & \multirow[t]{2}{*}{ DEHP } \\
\hline \multicolumn{5}{|l|}{ Transcription } & \\
\hline c-fos proto-oncogene & 3.00 & 0.45 & - & - & 0.52 \\
\hline \multicolumn{6}{|l|}{ Stress response proteins } \\
\hline Cytochrome P450 4F6 (Cyp4f6) & 3.00 & - & - & - & - \\
\hline \multicolumn{6}{|l|}{ Membrane channels and transporters } \\
\hline $\mathrm{Na}^{+}$channel, voltage-gated, type 1 , beta polypeptide (Scn1b) & 0.32 & - & - & - & - \\
\hline Slc6a3; Dopamine transporter (Dat1) & 2.29 & 0.35 & - & - & - \\
\hline Slc9al; $\mathrm{Na}^{+} / \mathrm{H}^{+}$exchanger 1 (Nhe 1$)$ & 3.43 & - & - & - & - \\
\hline Slca3; Glutamate/aspartate transporter (Glast) & 0.50 & - & - & - & 2.30 \\
\hline $\mathrm{H}^{+}$-ATPase, lysosomal (vacuolar proton pump) $16 \mathrm{kDa}$ (Atp6l) & 0.35 & - & - & - & - \\
\hline $\mathrm{H}^{+} / \mathrm{K}^{+}$-ATPase, nongastric, alpha polypeptide (Atp12a) & 9.20 & 0.54 & - & - & - \\
\hline \multicolumn{6}{|l|}{ Metabolism } \\
\hline Superoxide dismutase 1 (Sod 1$)$ & 0.44 & - & - & - & 2.27 \\
\hline Sterol carrier protein 2, liver (Scp2) & 5.27 & 0.43 & - & - & - \\
\hline \multicolumn{6}{|l|}{ Hydroxy-delta-5-steroid dehydrogenase, 3 beta- and steroid } \\
\hline delta-isomerase (Hsd3b) & 3.67 & - & - & - & - \\
\hline Cytochrome P450, subfamily 17 (Cyp 17 ) & 4.67 & - & - & - & 0.18 \\
\hline Thymidine kinase 1 (Tk1) & 14.11 & - & - & - & - \\
\hline \multicolumn{6}{|l|}{ Post-translational modification/protein folding } \\
\hline Heat shock $90-k D a$ protein beta (HSP90-beta) & 0.37 & - & - & - & 2.29 \\
\hline Heat shock $70 \mathrm{kD}$ protein $1 \mathrm{~A}$ (Hspala) & 1.73 & - & - & - & 0.29 \\
\hline \multicolumn{6}{|l|}{ Cell receptors (by ligands) } \\
\hline PDGF receptor, beta polypeptide (Pdgfrb) & 5.67 & - & - & - & - \\
\hline Insulin receptor (Insr) & 2.00 & - & - & - & - \\
\hline Dopamine receptor 1A (Drdla) & ND & - & - & - & 0.48 \\
\hline Dopamine receptor 2 (Drd2) & ND & - & - & ND & ND \\
\hline Dopamine receptor D4 (Drd4) & 1.90 & - & - & - & - \\
\hline Galanin receptor 2 (Galr2) & 2.33 & - & 0.43 & - & 0.26 \\
\hline Neurotensin receptor $2(\mathrm{Ntsr} 2)$ & 0.39 & - & ND & - & - \\
\hline Arginine vasopressin receptor 2 (Avpr2) & 2.75 & - & 0.44 & - & 0.25 \\
\hline Glutamate receptor, ionotropic, NMDA 1 (Grin1) & 0.56 & - & 0.59 & - & 0.41 \\
\hline \multicolumn{6}{|l|}{ Cell signaling, extracellular communication proteins } \\
\hline Neuropeptide Y (Npy) & 2.33 & - & - & - & 4.00 \\
\hline Tachykinin 2 (Tac2) & 7.86 & - & - & - & - \\
\hline Gastrin-releasing peptide (Grp) & 2.67 & - & - & - & - \\
\hline Fibroblast growth factor 10 (Fgf10) & 5.67 & - & - & 0.50 & 3.54 \\
\hline Somatostatin (Sst) & 0.43 & - & - & - & - \\
\hline Natriuretic peptide precursor $\mathrm{C}(\mathrm{Nppc})$ & 2.15 & - & 2.27 & 2.14 & 2.31 \\
\hline Insulin-like growth factor binding protein 6 (Igfbp6) & 2.00 & - & - & - & - \\
\hline
\end{tabular}

Multiple gene expression was examined by cDNA macroarray. Each value represents the ratio of gene expression level versus that of respective control value. This table lists the genes for which expression was above the threshold (expression ratios differed by more than 1.69 for an increment, less than 0.59 for a decrement) in rats treated with 6-OHDA. All the DA-related genes contained the Atlas Rat 1.2 are also listed. -, no change; ND, not determined since the density of gene expression was too weak to detect an alteration in the expression; Slc, solute carrier family; PDGF, platelet-derived growth factor. 
TABLE 3

Gene expression in the striatum altered by 6-OHDA or EDs.

\begin{tabular}{|c|c|c|c|c|c|}
\hline \multirow{2}{*}{ Classification, Gene name } & \multicolumn{5}{|c|}{ Expression ratio } \\
\hline & \multicolumn{4}{|c|}{ 6-OHDA Bisphenol A Nonylphenol p-Octylphenol } & \multirow[t]{2}{*}{ DEHP } \\
\hline \multicolumn{5}{|l|}{ Transcription } & \\
\hline c-fos proto-oncogene & 0.33 & - & - & - & 0.46 \\
\hline \multicolumn{6}{|l|}{ Stress response proteins } \\
\hline Cytochrome P450 4F6 (Cyp4f6) & 0.38 & ND & - & 1.89 & ND \\
\hline \multicolumn{6}{|l|}{ Membrane channels and transporters } \\
\hline $\mathrm{Na}^{+}$channel, voltage-gated, type 1 , beta polypeptide (Scnlb) & 2.33 & - & - & 0.47 & - \\
\hline Slc6a3; Dopamine transporter (Dat1) & 0.36 & ND & - & - & ND \\
\hline Slc6al 1; GABA transporter (Gat3) & 0.37 & - & 0.59 & - & - \\
\hline Slca3; Glutamate/aspartate transporter (Glast) & 1.88 & - & - & - & - \\
\hline $\mathrm{H}^{+}$-ATPase, lysosomal (vacuolar proton pump) $16 \mathrm{kDa}$ (Atp6l) & 2.50 & - & - & - & - \\
\hline Aquaporin 3 (Aqp3) & 0.42 & ND & - & - & ND \\
\hline \multicolumn{6}{|l|}{ Metabolism } \\
\hline Superoxide dismutase $1(\operatorname{Sod} 1)$ & 2.25 & - & - & 0.50 & - \\
\hline Sterol carrier protein 2, liver (Scp2) & 0.35 & - & - & - & - \\
\hline \multicolumn{6}{|l|}{ Hydroxy-delta-5-steroid dehydrogenase, 3 beta- and steroid } \\
\hline Cytochrome P450, subfamily 17 (Cyp17) & 0.46 & ND & - & - & ND \\
\hline \multicolumn{6}{|l|}{ Post-translational modification/protein folding } \\
\hline Heat shock $90-\mathrm{kDa}$ protein beta (HSP90-beta) & 2.27 & - & - & - & - \\
\hline Heat shock $70 \mathrm{kD}$ protein $1 \mathrm{~A}($ Hspala) & 0.48 & 0.43 & - & - & 0.43 \\
\hline \multicolumn{6}{|l|}{ Cell receptors (by ligands) } \\
\hline PDGF receptor, beta polypeptide (Pdgfrb) & 0.33 & - & - & - & ND \\
\hline Galanin receptor 2 (Galr2) & 0.30 & 0.50 & - & 1.76 & 0.50 \\
\hline Glutamate receptor, ionotropic, NMDA 1 (Grin1) & 0.40 & - & - & - & 0.10 \\
\hline Dopamine receptor 1A (Drd la) & ND & - & - & - & ND \\
\hline Dopamine recptor 2 (Drd2) & ND & - & - & - & ND \\
\hline Dopamine recptor 4 (Drd4) & ND & ND & - & - & ND \\
\hline \multicolumn{6}{|l|}{ Cell signaling, extracellular communication proteins } \\
\hline PDGF, B polypeptide (Pdgfb) & 0.48 & - & - & - & 0.55 \\
\hline
\end{tabular}

Results are represented as in Table 2.

substantia nigra pars compacta induced by nonylphenol and $p$-octylphenol. Similar results were found in rats treated with bisphenol A (Ishido, 2004). Therefore, these phenols may cause a deficit in the development of mesocorticolimbic DA neurons. Endogenous catecholamine levels should be further measured after these treatments. Furthermore, bisphenol A might induce apoptosis in central neural cells (Oka, 2003). Bisphenol A and nonylphenol stimulate hydroxy radical generation in the rat striatum (Obata, 2000). Taken together, neonatal treatment with phenols can cause neuronal cell death by stimulating hydroxy radical formation, as seen in the effects of 6-OHDA (Ferger, 2001), and 1-methyl- 
4-phenylpyridinium ion $\left(\mathrm{MPP}^{+}\right)$(Obata, 2001).

Diethylhexylphthalate treatment, however, did not cause a significant change in TH immunoreactivity in these regions. Thus, the mechanisms underlying hyperactivity might not be identical among EDs. Such different effects of EDs on DA neurons might result in a clinical variation of ADHD. It would be of interest to examine the effects of psychostimulants on the hyperactivity caused by EDs. Motor hyperactivity caused by hypofunction of DA might be attenuated by methylphenidate (Swanson, 1998; Volkow, 2002). Hyperactivity is also observed in methylphenidateinsensitive ADHD, however. The different effects of EDs can provide animal models for such clinical variation in this disorder.

To understand the mechanisms of hyperactivity, we first performed a cDNA array, using an Atlas Rat 1.2 membrane array manufactured by BD Biosciences Clontech. The results obtained by this method are closely related to those of the reverse transcription-linked polymerase chain reaction (RT-PCR) and real-time RT-PCR (Camerer, 2000; Cho, 2002; Goidin, 2000; Hester, 2003). To investigate the long-lasting effects of neonatal treatments, we measured gene expression at 8 weeks of age, although the hyperactivity caused by 6-OHDA lesions might be attenuated to control levels (Zhang, 2002). The decrease in gene expression observed here could not be due solely to the lack of DA neurons because we observed enhanced expression in several genes. Moreover, no difference was found between treated and control rats in the yield of RNA/tissue weight or in the integrity of the RNA in brain regions dissected out in the present study.

The effects of 6-OHDA lesions have been well documented; 6-OHDA affects the survival and the maintenance of DA neurons, thus triggering compensatory responses of the DA system. Recent studies with the DNA array technique demonstrated that several genes, including pleiotrophin, glialderived neurotrophic factor, protein kinase $\mathrm{A}$ subunit $\mathrm{C}$, and cyclin-dependent kinase 5, were upregulated in the rat striatum after an injection of 6-OHDA into the substantia nigra (Hida, 2003; Napolitano, 2002). Taken together, the changes in gene expression observed here seem to be due to DA-specific lesions and compensatory mechanisms. We should note, however, that we performed intracisternal injection of 6-OHDA and EDs on postnatal day 5 and motor hyperactivity was observed at 4 weeks of age. In previous studies (Hida, 2003; Napolitano, 2002), 6-OHDA was injected into the unilateral substantia nigra in the rat at 4 or 12 weeks of age, which is an animal model of Parkinson's disease. Thus, the present study is not comparable to these previous studies, and it remains to be possible that the changes in gene expression after neonatal treatment with 6OHDA and EDs are related to the mechanisms underlying motor hyperactivity.

In rats with neonatal 6-OHDA lesions, the expression of Glast was decreased in the mid-brain and enhanced in the striatum. The findings suggest that alterations in Glast, a high-affinity sodiumdependent glial glutamate/aspartate transporter, might play a part in the important role of motor hyperactivity and/or compensatory mechanisms in young adult rats with 6-OHDA lesions. In DEHPtreated rats, however, Glast expression was enhanced in the midbrain with no change in the striatum; other EDs did not cause a change in Glast in either region. In Grin 1, which encodes the NMDA receptor 1, expression was decreased in the midbrain and striatum by 6-OHDA. In the midbrain, nonylphenol and DEHP, but not bisphenol $\mathrm{A}$ and p-octylphenol, also caused a decrease in the expression. In the striatum, DEHP also caused a decrease in the expression. The striatum is a region rich in NMDA receptors (Gracy, 1999; Petralia, 1994; Tarazi, 1999), and corticostriatal glutamatergic neurons stimulate DA release from the striatum (Taber, 1993) via NMDA receptors (Ochi, 1995). Thus, the present results suggest that glutamatergic transmission via NMDA 
receptors can be attenuated in the striatum during early adulthood. Taken together, an inhibition of glutamatergic transmission in the midbrain and striatum may be involved in changes in motor activity caused by 6-OHDA, nonyl-phenol, and DEHP.

The finding that 6-OHDA lesions caused an increase in Dat 1 expression in the midbrain supports the results of previous studies suggesting an augmentation in the expression of the DA transporter 1 in patients with ADHD (Madras, 2002; Roman, 2001). The expression of Dat 1 can be increased in DA neurons that are resistant to 6-OHDA treatment and/or in non-DA elements (Hoffman, 1998). On the contrary, a decrement of Dat 1 expression can be due to the lack of DAergic terminals in the striatum. Bisphenol A caused a decrease in Datl expression in the midbrain with no changes caused by other environmental chemicals. Possibly other EDs caused a deficit not only in the DA system but also in other systems. The expression of Drd4 was also enhanced in the midbrain after 6-OHDA, which supports the results of previous studies suggesting that $\mathrm{D} 4$ receptors are implicated in clinical ADHD (DiMaio, 2003). The induction of Dat 1 and Drd4 expression in the midbrain can contribute to the efficiency of psychostimulants like methylphenidate in motor hyperactivity. The effects of psychostimulants on SMA should be further investigated in rats receiving neonatal treatment with EDs in comparison with animals with 6OHDA lesions.

After the 6-OHDA lesions, we also observed alterations in the expression of several classes of genes. Expression was increased in genes coding cell receptors such as Pdgfrb, Insr, Galr2, and Avpr2, and in cell-signaling extracellular communication proteins, such as Npy, Tac2, Grp, Fgf10, Nppc, and Igfbp6 in the midbrain. In these genes, the expression profiles in rats treated with EDs were different from those obtained with 6-OHDA. The expression of Npy, however, was also increased after DEHP treatment, and an enhanced expression of Nppc was similarly found after the injection of nonylphenol, $p$-octylphenol, and DEHP. Among these, galanin has been suggested to interact with DA neurons in the midbrain (Counts, 2002) and striatum (Ericson, 1999; Tsuda, 1998). It was demonstrated that arginine vasopression (Iqbal, 1995) and GRP (Larsen, 1989) are expressed in the substantia nigra. These peptides might be also involved in motor hyperactivity and/ or compensatory changes with different roles in the regulation of the mesostriatal system.

We studied gene expression in the midbrain and striatum to investigate mechanisms underlying motor hyperactivity. It was suggested, however, that the frontal cortex and ventral striatum, including the nucleus accumbens, play important roles in behavior and cognition in ADHD (SonugaBarke, 2002; 2003). A defect in neuronal circuits required for reward-guided associative learning and memory formation might be due to a deficit in glutamate-evoked release in the nucleus accumbens in ADHD patients (Russell, 2003). The frontal cortex can also play an important role in ADHD (Russell, 2002). Moreover, it was suggested that the altered neurotransmission of noradrenaline and serotonin is involved in ADHD and/or motor hyperactivity (Blanc, 1994; Davids, 2002a). In the present study, altered expression was not observed in genes encoding adrenergic and serotonergic elements although the Atlas Rat 1.2 (BD Biosciences Clontech) ${ }^{1}$ contained several classes of adrenergic and serotonergic receptors. Thus, multiple gene expression should be further investigated in the nucleus accumbens and in the frontal cortex.

The present study has demonstrated motor hyperactivity in rats neonatally treated with 6-OHDA and EDs. Among the EDs, phenols, but

\footnotetext{
$1 \mathrm{http}: / / \mathrm{www} . \mathrm{bdbiosciences.com/clontech/atlas/genelists/index.}$ shtml
} 
not a phthalate, might cause the deficit in the development of mesostriatal DA neurons. The results of the DNA array suggest that the transmission of glutamate, DA, and other factors including neuropeptides, can be crucial in motor hyperactivity and/or compensatory mechanisms by the lack of DA neurons. The alteration patterns of gene expression by EDs differed from those of 6-OHDA, however, and these were not identical among EDs. The results suggest that neonatal treatment with EDs can provide an animal model of ADHD in which clinical symptoms are pervasive. The present study focusing on mesostriatal DA neurons prompts further investigation of multiple gene expression in the frontal cortex and ventral striatum to understand the mesocorticolimbic variants underlying ADHD.

\section{ACKNOWLEDGMENTS}

This work was supported by the Ministry of Economy, Trade, and Industry, Japan, and the Ministry of the Environment, Japan. Y.M. was a recipient of a fellowship from the New Energy and Industrial Technology Development Organization (NEDO) during this study.

\section{REFERENCES}

Blanc G, Trovero F, Vezina P, Herve D, Godeheu AM, Glowinski J, et al. 1994. Blockade of prefronto-cortical alpha 1-adrenergic receptors prevents locomotor hyperactivity induced by subcortical D-amphetamine injection. Eur J Neurosci 6: 293-298.

Camerer E, Gjernes E, Wiiger M, Pringle S, Prydz H. 2000. Binding of factor VIIa to tissue factor on keratinocytes induces gene expression. J Biol Chem 275: 6580-6585.

Cho KS, Choi J, Ha CM, Son YJ, Choi WS, Lee BJ. 2002. Comparison of gene expression in old versus young rat hippocampus by cDNA array. Neuroreport 13: 285-289.
Counts SE, McGuire SO, Sortwell CE, Crawley JN, Collier TJ, Mufson EJ. 2002. Galanin inhibits tyrosine hydroxylase expression in midbrain dopaminergic neurons. J Neurochem 83: 442-451.

Davids E, Zhang K, Kula NS, Tarazi FI, Baldessarini RJ. 2002a. Effects of norepinephrine and serotonin transporter inhibitors on hyperactivity induced by neonatal 6-hydroxydopamine lesioning in rats. $\mathrm{J}$ Pharmacol Exp Ther 301: 1097-1102.

Davids E, Zhang K, Tarazi FI, Baldessarini RJ. $2002 \mathrm{~b}$. Stereoselective effects of methylphenidate on motor hyperactivity in juvenile rats induced by neonatal 6-hydroxydopamine lesioning. Psychopharmacology (Berl) 160: 92-98.

DiMaio S, Grizenko N, Joober R. 2003. Dopamine genes and attention-deficit hyperactivity disorder: a review. J Psychiatry Neurosci 28: 27-38.

Ericson E, Ahlenius S. 1999. Suggestive evidence for inhibitory effects of galanin on mesolimbic dopaminergic neurotransmission. Brain Res 822: 200-209.

Ferger B, Rose S, Jenner A, Halliwell B, Jenner P. 2001. 6-hydroxydopamine increases hydroxyl free radical production and DNA damage in rat striatum. Neuroreport 12: 1155-1159.

Foehr ED, Lin X, O'Mahony A, Geleziunas R, Bradshaw RA, Greene WC. 2000. NF-kappa B signaling promotes both cell survival and neurite process formation in nerve growth factorstimulated PC12 cells. J Neurosci 20: 7556-7563.

Goidin D, Kappeler L, Perrot J, Epelbaum J, Gourdji D. 2000. Differential pituitary gene expression profiles associated to aging and spontaneous tumors as revealed by rat cDNA expression array. Endocrinology 141: 4805-4808.

Gracy KN, Clarke CL, Meyers MB, Pickel VM. 1999. $\mathrm{N}$-methyl-D-aspartate receptor 1 in the caudateputamen nucleus: ultrastructural localization and co-expression with sorcin, a $22,000 \mathrm{~mol}$. wt calcium binding protein. Neuroscience 90: 107-117.

Heffner TG, Seiden LS. 1982. Possible involvement of serotonergic neurons in the reduction of locomotor hyperactivity caused by amphetamine in neonatal rats depleted of brain dopamine. Brain Res 244: 81-90.

Hester SD, Benavides GB, Yoon L, Morgan KT, Zou F, Barry W, et al. 2003. Formaldehyde-induced gene expression in F344 rat nasal respiratory epithelium. Toxicology 187: 13-24.

Hida $\mathrm{H}$, Jung CG, Wu CZ, Kim HJ, Kodama Y, 
Masuda T, et al. 2003. Pleiotrophin exhibits a trophic effect on survival of dopaminergic neurons in vitro. Eur J Neurosci 17: 2127-2134.

Hoffman BJ, Hansson SR, Mezey E, Palkovits M. 1998. Localization and dynamic regulation of biogenic amine transporters in the mammalian central nervous system. Front Neuroendocrinol 19: 187-231.

Iqbal J, Jacobson CD. 1995. Ontogeny of arginine vasopressin-like immunoreactivity in the Brazilian opossum brain. Brain Res Dev Brain Res 89: 11-32.

Ishido M, Masuo $\mathrm{Y}$, Oka S, Kunimoto M, Morita M. 2004. Bisphenol A causes hyperactivity in the rat concomitantly with impairment of tyrosine hydroxylase immunoreactivity. J Neurosci Res 76: 423-433.

Ishido $\mathrm{M}$, Masuo $\mathrm{Y}$, Oka S, Kunimoto $\mathrm{M}$, Morita $\mathrm{M}$. 2002. Application of Supermex system to screen behavioral traits produced by tributyltin in the rat. J Health Sci 48: 451-454.

Kuppers E, Ivanova T, Karolczak M, Lazarov N, Fohr K, Beyer C. 2001. Classical and nonclassical estrogen action in the developing midbrain. Horm Behav 40: 196-202.

Larsen PJ, Saermark T, Mikkelsen JD. 1989. An immunohistochemical demonstration of gastrinreleasing peptide (GRP) in the rat substantia nigra. J Chem Neuroanat 2: 83-93.

Madras BK, Miller GM, Fischman AJ. 2002. The dopamine transporter: relevance to attention deficit hyperactivity disorder (ADHD). Behav Brain Res 130: 57-63

Markey CM, Rubin BS, Soto AM, Sonnenschein C. 2002. Endocrine disruptors: from Wingspread to environmental developmental biology. J Steroid Biochem Mol Biol 83: 235-244.

Masuo Y, Ishido M, Morita M, Oka S. 2002. Effects of neonatal 6-hydroxydopamine lesion on the gene expression profile in young adult rats. Neurosci Lett 335: 124-128.

Masuo Y, Noguchi J, Morita S, Matsumoto Y. 1995. Effects of intracerebroventricular administration of pituitary adenylate cyclase-activating polypeptide (PACAP) on the motor activity and reserpine-induced hypothermia in murines. Brain Res 700: 219-226.

Mori C. 2001. Assessment of fetal environmental exposure and subtle male reproductive disorders in Japan. Proceedings of the $1^{\text {st }}$ U.S.-Japan Workshop on Endocrine Disrupting Chemicals and Their Toxicological Evaluation. 103-106.

Napolitano M, Centonze D, Calce A, Picconi B, Spiezia S, Gulino A, et al. 2002. Experimental parkinsonism modulates multiple genes involved in the transduction of dopaminergic signals in the striatum. Neurobiol Dis 10: 387-395.

Obata T, Kubota S. 2000. Formation of hydroxy radicals by environmental estrogen-like chemicals in rat striatum. Neurosci Lett 296: 41-44.

Obata T, Kubota S, Yamanaka Y. 2001. Protective effect of histidine on para-nonylphenol-enhanced hydroxyl free radical generation induced by 1 methyl-4-phenylpyridinium ion (MPP+) in rat striatum. Biochim Biophys Acta 1568: 171-175.

Ochi M, Inoue H, Koizumi S, Shibata S, Watanabe S. 1995. Long-term enhancement of dopamine release by high frequency tetanic stimulation via a $\mathrm{N}$ methyl-D-aspartate-receptor-mediated pathway in rat striatum. Neuroscience 66: 29-36.

Oka T, Adati N, Shinkai T, Sakuma K, Nishimura T, Kurose K. 2003. Bisphenol A induces apoptosis in central neural cells during early development of Xenopus laevis. Biochem Biophys Res Commun 312: 877-882.

Palanza P, Morellini F, Parmigiani S, vom Saal FS. 1999. Prenatal exposure to endocrine disrupting chemicals: effects on behavioral development. Neurosci Biobehav Rev 23: 1011-1027.

Petralia RS, Yokotani N, Wenthold RJ. 1994. Light and electron microscope distribution of the NMDA receptor subunit NMDAR1 in the rat nervous system using a selective anti-peptide antibody. J Neurosci 14: 667-696.

Roman T, Schmitz M, Polanczyk G, Eizirik M, Rohde LA, Hutz MH. 2001. Attention-deficit hyperactivity disorder: a study of association with both the dopamine transporter gene and the dopamine D4 receptor gene. Am J Med Genet 105: 471-478.

Russell VA. 2002. Hypodopaminergic and hypernoradrenergic activity in prefrontal cortex slices of an animal model for attention-deficit hyperactivity disorder-the spontaneously hypertensive rat. Behav Brain Res 130: 191-196.

Russell VA. 2003. Dopamine hypofunction possibly results from a defect in glutamate-stimulated release of dopamine in the nucleus accumbens shell of a rat model for attention deficit hyperactivity disorder-the spontaneously hypertensive rat. Neurosci Biobehav Rev 27: 671-682.

Shaywitz BA, Klopper JH, Yager RD, Gordon JW. 
1976a. Paradoxical response to amphetamine in developing rats treated with 6- hydroxydopamine. Nature 261: 153-155.

Shaywitz BA, Yager RD, Klopper JH. 1976 b. Selective brain dopamine depletion in developing rats: an experimental model of minimal brain dysfunction. Science 191: 305-308.

Sonuga-Barke EJ. 2002. Psychological heterogeneity in $\mathrm{AD} / \mathrm{HD}-\mathrm{a}$ dual pathway model of behaviour and cognition. Behav Brain Res 130: 29-36.

Sonuga-Barke EJ. 2003. The dual pathway model of $\mathrm{AD} / \mathrm{HD}$ : an elaboration of neuro-developmental characteristics. Neurosci Biobehav Rev 27: 593-604.

Swanson JM, Sergeant JA, Taylor E, Sonuga-Barke EJ, Jensen PS, Cantwell DP. 1998. Attentiondeficit hyperactivity disorder and hyperkinetic disorder. Lancet 351: 429-433.

Swanson JM, Volkow ND. 2003. Serum and brain concentrations of methylphenidate: implications for use and abuse. Neurosci Biobehav Rev 27: 615-621.

Taber MT, Fibiger HC. 1993. Electrical stimulation of the medial prefrontal cortex increases dopamine release in the striatum. Neuropsychopharmacology 9: 271-275.

Tarazi FI, Baldessarini RJ. 1999. Regional localization of dopamine and ionotropic glutamate receptor subtypes in striatolimbic brain regions. J Neurosci Res 55: 401-410.

Tsuda K, Tsuda S, Nishio I, Masuyama Y, Goldstein M. 1998. Effects of galanin on dopamine release in the central nervous system of normotensive and spontaneously hypertensive rats. Am J Hypertens 11: 1475-1479.

Viggiano D, Vallone D, Ruocco LA, Sadile AG. 2003. Behavioural, pharmacological, morpho-functional molecular studies reveal a hyperfunctioning mesocortical dopamine system in an animal model of attention deficit and hyperactivity disorder. Neurosci Biobehav Rev 27: 683-689.

Volkow ND, Fowler JS, Wang GJ, Ding YS, Gatley SJ. 2002. Role of dopamine in the therapeutic and reinforcing effects of methylphenidate in humans: results from imaging studies. Eur Neuropsychopharmacol 12: 557-566.

Zhang K, Tarazi FI, Baldessarini RJ. 2001. Role of dopamine $\mathrm{D}(4)$ receptors in motor hyperactivity induced by neonatal 6-hydroxydopamine lesions in rats. Neuropsychopharmacology 25: 624-632.

Zhang K, Tarazi FI, Davids E, Baldessarini RJ. 2002. Plasticity of dopamine D4 receptors in rat forebrain: temporal association with motor hyperactivity following neonatal 6-hydroxydopamine lesioning. Neuropsychopharmacology 26: 625-633. 

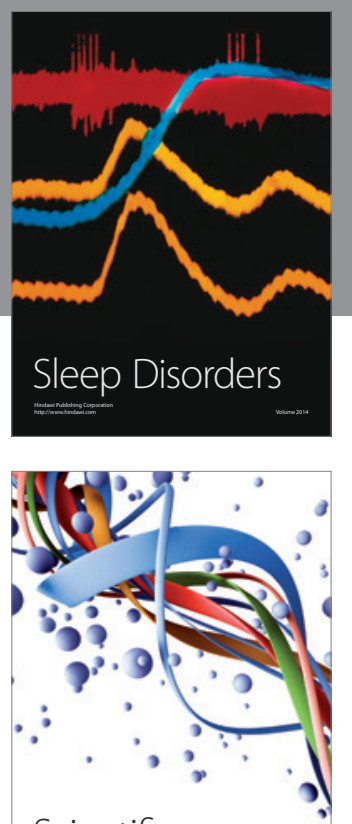

Scientifica
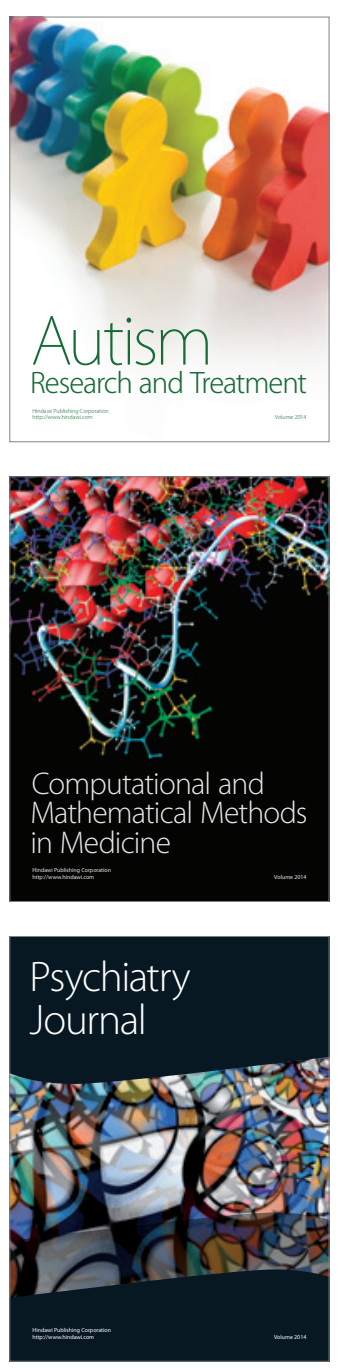
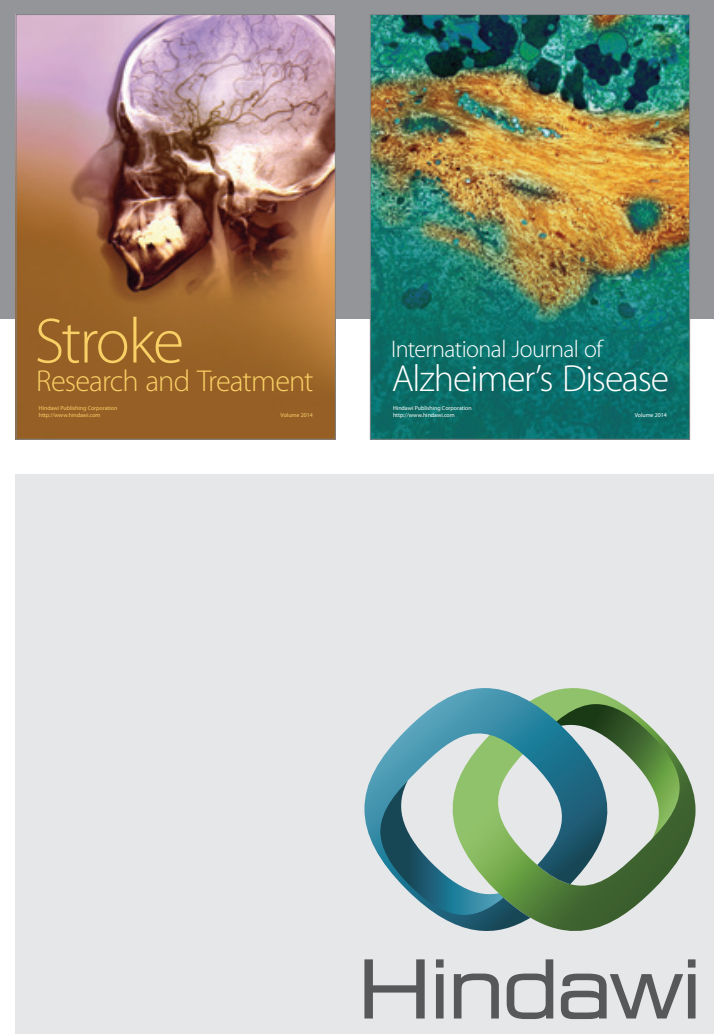

Submit your manuscripts at

http://www.hindawi.com
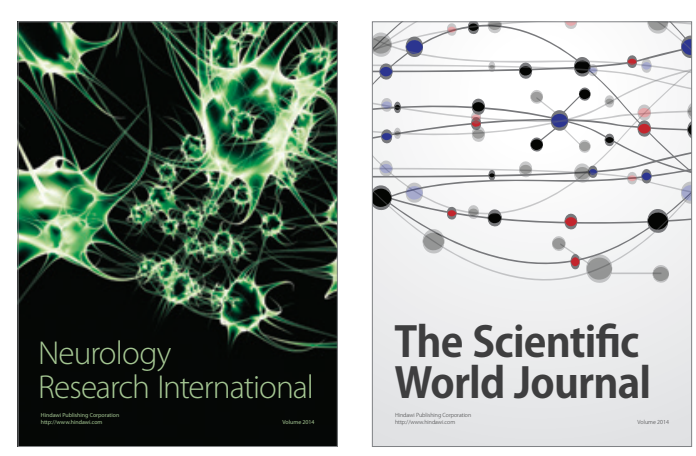

The Scientific World Journal

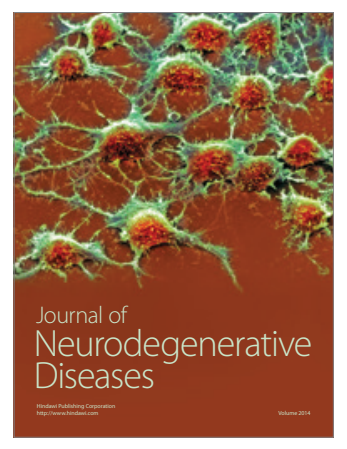

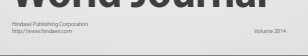

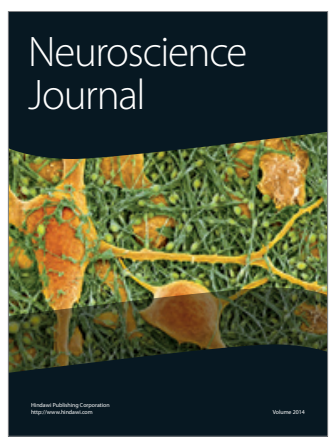

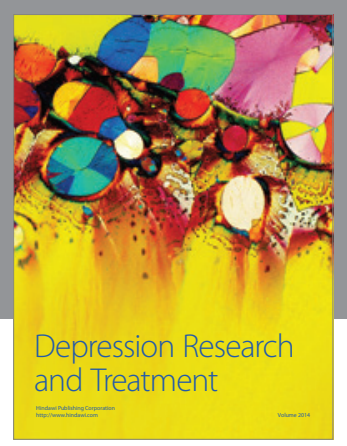
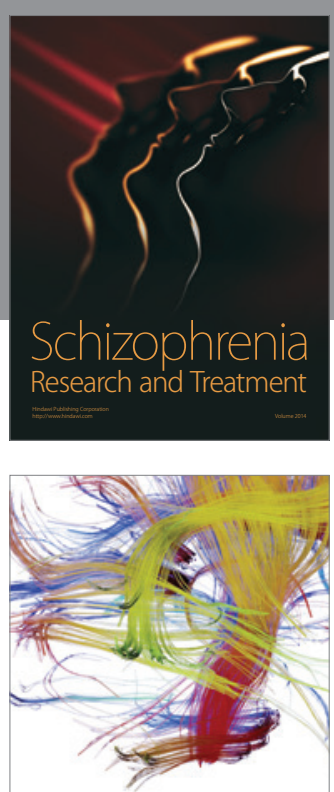

Brain Science

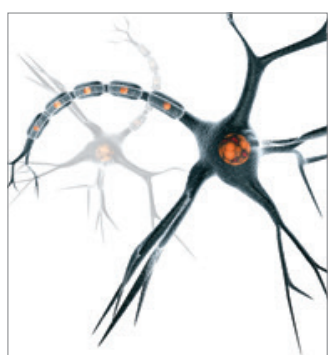

Neural Plasticity
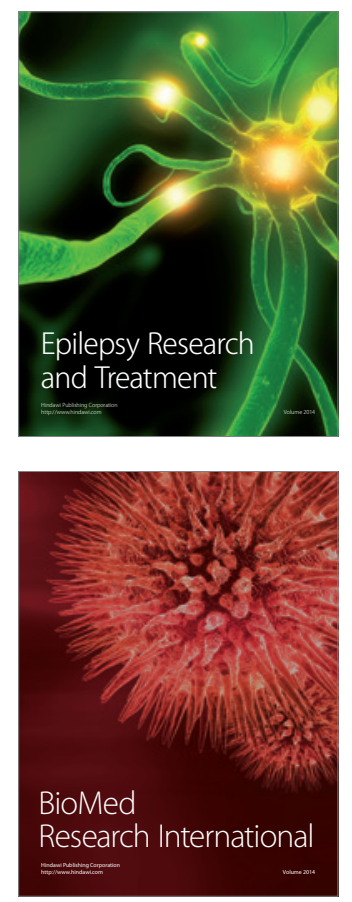

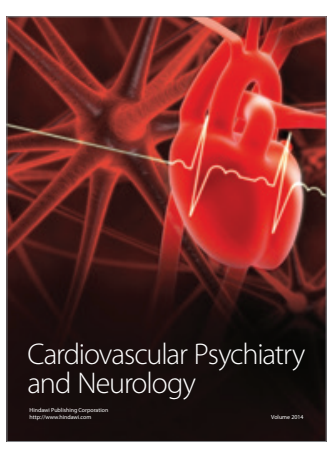

Parkinson's

Disease
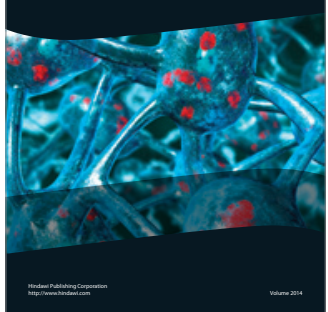